\title{
LEUCEMIA LINFOCÍTICA B EM CÃO JOVEM: RELATO DE CASO
}

\author{
Ivan Felismino Charas dos Santos ${ }^{1}$ \\ Giovanna Cristina Brombini ${ }^{2}$ \\ Filipe Issac Tannus ${ }^{2}$ \\ Mayara Viana Freire Gomes ${ }^{2}$ \\ Mariana Gomez Reis ${ }^{3}$ \\ Amanda Carla Garcia Assis ${ }^{3}$
}

SANTOS, I. F. C. dos; BROMBINI, G. C.; TANNUS, F. I.; GOMES, M. V. F.; REIS, M. G.; ASSIS, A. C. G. Leucemia linfocítica B em cão jovem: relato de caso. Arq. Ciênc. Vet. Zool. UNIPAR, Umuarama, v. 19, n. 2, p. 113-119, abr./jun. 2016.

RESUMO: O presente relato teve como objetivo descrever um caso de leucemia linfocítica B em um cão da raça maltês, fêmea, com três anos de idade, demonstrando a metodologia de diagnóstico e a variação da patologia clínica após o tratamento exclusivamente por esplenectomia. A linfocitose acentuada observada no hemograma e presença proliferativa de linfócitos na medula óssea determinou a suspeita da leucemia linfocítica. A leucemia linfocítica B foi diagnosticada por meio da citologia aspirativa da medula óssea, imunocitoquímica e citometria de fluxo. O tratamento foi exclusivamente por esplenectomia e dois anos após a cirurgia o animal não apresentou recidiva da afecção.

PALAVRAS-CHAVE: Doenças linfoproliferativas. Linfócitos. Imunocitoquimica. Medula óssea. Pequenos animais.

\section{B - LYMPHOCYTIC LEUKEMIA IN YOUNG DOG: CASE REPORT}

\begin{abstract}
This report aimed to describe a case of B lymphocytic leukemia in maltese female dog, three years old, demonstrating the methodology of diagnostic and variation of clinical pathology after treatment exclusively by splenectomy. The accentuate lymphocytes observed in blood counts and presence of proliferative lymphocytes in the bone marrow were determined to diagnostic of lymphocytic leukemia. The B lymphocytic leukemia was diagnosed by bone marrow aspiration cytology, immunocytochemistry and flow cytometry. The treatment was exclusively by splenectomy and two years after the surgery the animal showed no recurrence of the disease.
\end{abstract}

KEY WORDS: Linfoproliferative disease. Lymphocytes. Immunocytochemistry. Bone marrow. Small animals.

\section{LEUCEMIA LINFOCÍTICA B EN PERRO JOVEN: RELATO DE CASO}

RESUMEN: El objetivo de ese relato ha sido describir un caso de leucemia linfocítica B en un perro, raza maltés, hembra, de tres años, demostrando la metodología de diagnóstico y la variación de la patología clínica, después del tratamiento exclusivamente por esplenectomía. La linfocitosis aguda, observada en el hemograma, y la presencia de proliferación de linfocitos en la médula ósea, determinó la sospecha de leucemia linfocítica. La leucemia linfocítica B fue diagnosticada mediante la citología por aspiración de médula ósea, inmunocitoquímica y citometría de flujo. El tratamiento fue exclusivamente por esplenectomía y dos años después de la cirugía el animal no mostró recurrencia de la enfermedad.

PALABRAS CLAVE: Enfermedades linfoproliferativas. Linfocitos. Inmunocitoquímica. Médula ósea. Pequeños animales.

Introdução

A leucemia linfocítica é uma afecção maligna e progressiva, marcada por uma proliferação desordenada de linfócitos maduros morfologicamente normais na medula óssea ou no sangue periférico (SHIMOMURA, 2006; DOBSON, 2006; FRANCO, 2008). De acordo com a linhagem leucocitária afetada, as leucemias são classificadas como linfoide e mieloide (HARVEY, 2001). Segundo Lorenzi (2006), a leucemia linfocítica em pacientes humanos é considerada benigna quando comparadas com outro tipo de leucemias. É relatada em cães idosos e sem predileção por raça (SHIMOMURA, 2006; DOBSON, 2006). A idade média dos cães acometidos é de 9,4 anos, e a relação macho e fêmea é de 2:1 (TILLEY, 2003).
Os sinais clínicos são inespecíficos, mas pode-se observar letargia, anorexia, perda de peso, vômito, diarreia intermitente, poliúria, polidipsia e pirexia (SHIMOMURA, 2006; DOBSON, 2006). O histórico de cronicidade dos sinais clínicos precede o diagnóstico da leucemia linfocítica em aproximadamente metade dos cães acometidos (SHIMOMURA, 2006). Por outro lado, a afecção pode ser identificada como achado incidental de linfocitose no hemograma de rotina (SHIMOMURA, 2006; DOBSON, 2006; FRANCO, 2008).

O diagnóstico tem início com a caracterização morfológica utilizando-se colorações de Romanowsky. Apesar de bastante útil, essa não é suficiente para um diagnóstico definitivo; sendo assim, faz-se necessário a confirmação por colorações citoquímicas, imunofenotipagem e estudo ultra-

DOI: https://doi.org/10.25110/arqvet.v19i2.2016.5931

${ }^{1}$ Pós-doutorando (FAPESP) de Cirurgia Veterinária. Universidade Estadual Paulista (UNESP). Faculdade de Medicina Veterinária e Zootecnia (FMVZ). Departamento de Cirurgia e Anestesiologia Veterinária. Campus de Botucatu, SP. E-mail: ivansantos7@hotmail.com

${ }^{2}$ Universidade Estadual Paulista (UNESP). Faculdade de Medicina Veterinária e Zootecnia (FMVZ). Departamento de Cirurgia e Anestesiologia Veterinária. Campus de Botucatu, SP

${ }^{3}$ Faculdade de Ensino Superior e Formação Integral (FAEF), Curso de Medicina Veterinária. Garça, SP 
estrutural (SHIMOMURA, 2006). O diagnóstico diferencial é considerado limitado devido à baixa porcentagem de afecções que causem linfocitose acentuada (SHIMOMURA, 2006). Porém, é importante diferenciar de linfossarcoma e doenças hematológicas imunomediada (TILLEY, 2003). Doenças como a erliquiose, babesiose e leishmaniose devem ser inclusas no diagnóstico diferencial (SHIMOMURA, 2006; FRANCO, 2008).

O tratamento tem como objetivo diminuir a proliferação de clones neoplásicos sem causar total ablação da medula óssea (TILLEY, 2003; SHIMOMURA, 2006). Segundo Tilley (2003) e Shimomura (2006), o tratamento não é instituído até que haja sinais clínicos significativos de anemia, neutropenia e trombocitopenia. A quimioterapia é indicada apenas quando o paciente for sintomático, e a esplenectomia é realizada quando existe anemia hemolítica imunomediada secundária ou trombocitopenia grave (TILLEY, 2003).

Visto que a leucemia linfocítica B é considerada uma afecção rara em cães, e quando presente acomete cães idosos, o presente trabalho tem como objetivo descrever um caso de leucemia linfocítica B em uma cadela com dois anos de idade, analisando a metodologia de diagnóstico e a variação da patologia clínica após o tratamento exclusivamente por esplenectomia.

\section{Relato do caso}

Cadela de raça maltesa, três anos de idade, $8 \mathrm{~kg}$ de peso corporal e submetida à ováriohisterectomia com 14 meses de idade, foi atendida em consulta de rotina anual. $\mathrm{O}$ proprietário relatou normodipsia, normouria, normofagia e normoquesia. O exame físico não evidenciou quaisquer anormalidades. Foi coletada uma amostra de sangue para a realização do hemograma (eritrograma, leucograma e contagem total de plaquetas) e exame bioquímico sérico (alanina aminotransferase - ALT e creatinina - CREAT). A urina foi coletada por cistocentese para posterior realização da urinálise.

O sangue destinado à realização do eritrograma e do leucograma foi depositado em tubo plástico contendo o ácido etilenodiaminotetracético (EDTA) como anticoagulante. Os parâmetros referentes à contagem de eritrócitos, hemoglobina, leucócitos totais e plaquetas foram analisadas pelo contador eletrônico de células Ebram 18 hemascreen ${ }^{1}$. Para a contagem diferencial dos leucócitos utilizou-se um esfregaço de sangue corado pelo corante hematológico de Wright e examinado ao microscópio na objetiva de imersão a óleo (100 x). O sangue para os exames de bioquímica sanguínea sérica foi depositado em tubo plástico sem adição de anticoagulante. Posteriormente foi centrifugado (1.500 rpm, 15 minutos) e o soro foi acondicionado em frascos de Eppendorf para posterior dosagem da ALT e CREAT, utilizando o kit comercial Labtest ${ }^{2}$. A urina foi centrifugada (1.800 rpm, 10 minutos) e o sobrenadante foi separado do sedimento. Em seguida, o sobrenadante foi utilizado para a realização do exame físico (densidade específica) utilizando o refratômetro e exame químico (proteínas, glicose, nitrito, bilirrubina, corpos cetônicos, leucócitos, sangue e urobilinogênio e $\mathrm{pH}$ urinário) utilizando a fita de polieletrólitos ComburTest ${ }^{3}$. A análise físico-química foi realizada mediante observação do

${ }^{1}$ Ebram Produtos Laboratoriais Ltda, Belenzinho, Brasil.

${ }^{2}$ Labtest Diagnóstica, Lagoa Santa, Minas Gerais, Brasil.

${ }^{3}$ Roche Diagnóstica Brasil Ltda, São Paulo, Brasil. aspecto e coloração da urina. A análise microscópica foi realizada após a centrifugação, sendo quantificadas as células epiteliais, cristais, leucócitos, hemácias, bactérias, filamento de muco e cilindros.

Os valores do eritrograma, bioquímica sérica (ALT e CREAT) e da urinálise permaneceram dentro dos padrões de referência da espécie (Tabela 1, 2 e 3), porém, em relação ao leucograma, foi observada leucocitose, neutrofilia, linfocitose e diversas sombras de Gumprecht, representando pequenos linfócitos maturos rupturados durante a execução do esfregaço sanguíneo, com formação de restos linfocitários, e frequentemente estão relacionadas com a leucemia linfocítica crônica.

Tabela 1: Valores do eritrograma, leucograma e contagem total de plaquetas no primeiro dia de consulta, de cadela de raça maltesa, três anos de idade, oito quilos de peso corpóreo (São Paulo, 2014).

\begin{tabular}{lcc}
\hline \multicolumn{1}{c}{ Parâmetros } & Resultado & $\begin{array}{c}\text { Valor de } \\
\text { referência } \\
\text { (JAIN, 1986) }\end{array}$ \\
\hline Eritrócitos $(106 / \mu \mathrm{L})$ & 7,2 & $5,5-8,5$ \\
Hemoglobina $(\mathrm{g} / \mathrm{dL})$ & 14,9 & $12-18$ \\
Hematócrito $(\%)$ & 48 & $37-55$ \\
Leucócitos totais $(/ \mu \mathrm{L})$ & 58.000 & $6.000-17.000$ \\
Neutrófilos bastonetes & 0 & $0-300$ \\
$(/ \mu \mathrm{L})$ & & \\
Neutrófilos segmentados & 17.400 & $3.000-11.500$ \\
$(/ \mu \mathrm{L})$ & 38.800 & $1.000-4.800$ \\
Linfócitos $(/ \mu \mathrm{L})$ & 1.200 & $150-1.350$ \\
Monócitos $(/ \mu \mathrm{L})$ & 600 & $100-1.250$ \\
Eosinófilos $(/ \mu \mathrm{L})$ & 438.000 & $200.000-500.000$ \\
Plaquetas $(/ \mu \mathrm{L})$ & &
\end{tabular}

Tabela 2: Valores da bioquímica sanguínea sérica (ALT e CREAT) no primeiro dia de consulta, de cadela de raça maltesa, três anos de idade, $8 \mathrm{~kg}$ de peso corpóreo (São Paulo, 2014).

\begin{tabular}{lcc}
\hline \multicolumn{1}{c}{ Parâmetros } & Resultado & $\begin{array}{c}\text { Valores de referência } \\
\text { (KANEKO et al., 2008) }\end{array}$ \\
\hline ALT (UI/L) & 29 & $21-102$ \\
CREAT (mg/dL) & 0,74 & $0,5-1,5$ \\
\hline
\end{tabular}

Tabela 3: Valores da urinálise no primeiro dia de consulta, de cadela de raça maltesa, três anos de idade, oito quilos de peso corpóreo (São Paulo, 2014).

\begin{tabular}{lcc}
\hline \multicolumn{1}{c}{ Parâmetros } & Resultados & $\begin{array}{c}\text { Valores de referência } \\
\text { (KANEKO et al., 2008) }\end{array}$ \\
\hline Aspecto & Turvo & Límpido \\
Cor & Amarelo & Amarelo \\
Densidade & 1,020 & $1,018-1,045$ \\
pH & 6,0 & $5-6,5$ \\
Sangue & Negativo & Negativo \\
Proteína (mg/dl) & Negativo & Negativo \\
Glicose & Negativo & Negativo
\end{tabular}




$\begin{array}{lcc}\text { Corpos cetônicos } & - & \text { Negativo } \\ \text { Bilirrubina } & \text { Negativo } & \text { Negativo } \\ \text { Urobilinogênio } & \text { Normal } & \text { Normal } \\ \text { Eritrócitos } & \text { Ausentes } & \text { Ausentes } \\ \text { Leucócitos } / \mu \mathrm{L} & 1 & 1 \text { a } 2 / \text { campo } \\ \text { Células epiteliais } & \text { Ausentes } & \text { Ausentes } \\ \text { Cilindros } & \text { Ausentes } & \text { Ausentes } \\ \text { Cristais } & \text { Ausentes } & \text { Ausentes }\end{array}$

Posteriormente, foi realizado um exame ultrassonográfico abdominal e não foram observados quaisquer sinais de alterações. De acordo com os resultados do leucograma foi prescrito cefalexina ${ }^{4}$ [25 mg/kg, via oral (VO), a cada 12 horas (BID)] durante sete dias. Dez dias após, o animal retornou e foram realizados hemograma e exame bioquímico sérico (ALT e CREAT). Os respectivos valores permaneceram dentro dos padrões de referência da espécie, excetuando uma discreta diminuição dos valores dos leucócitos e linfócitos (Tabelas 4 e 5). Foram observadas sombras de Gumprecht.

Tabela 4: Valores do eritrograma, leucograma e contagem total de plaquetas, 10 dias após o início do tratamento, de cadela de raça maltesa, três anos de idade, oito quilos de peso corpóreo (São Paulo, 2014).

\begin{tabular}{lcc}
\hline \multicolumn{1}{c}{ Parâmetros } & Resultado & $\begin{array}{c}\text { Valor de referência } \\
(\mathrm{JAIN}, 1986)\end{array}$ \\
\hline Eritrócitos $(106 / \mu \mathrm{L})$ & 5,6 & $5,5-8,5$ \\
Hemoglobina $(\mathrm{g} / \mathrm{dL})$ & 12,8 & $12-18$ \\
Hematócrito $(\%)$ & 46 & $37-55$ \\
Leucócitos totais $(/ \mu \mathrm{L})$ & 23.300 & $6.000-17.000$ \\
Neutrófilos bastonetes & 0 & $0-300$ \\
$(/ \mu \mathrm{L})$ & & \\
Neutrófilos segmentados & 9.500 & $3.000-11.500$ \\
$(/ \mu \mathrm{L})$ & 12.200 & $1.000-4.800$ \\
Linfócitos $(/ \mu \mathrm{L})$ & 1.100 & $150-1.350$ \\
Monócitos $(/ \mu \mathrm{L})$ & 500 & $100-1.250$ \\
Eosinófilos $(/ \mu \mathrm{L})$ & 319.000 & $200.000-500.000$ \\
Plaquetas $(/ \mu \mathrm{L})$ & &
\end{tabular}

Tabela 5. Valores da bioquímica sanguínea sérica (ALT e CREAT), 10 dias após o início do tratamento, de cadela de raça maltesa, três anos de idade, $8 \mathrm{~kg}$ de peso corpóreo (São Paulo, 2014).

\begin{tabular}{lcc}
\hline \multicolumn{1}{c}{ Parâmetros } & Resultado & $\begin{array}{c}\text { Valores de referência } \\
\text { (KANEKO et al., 2008) }\end{array}$ \\
\hline ALT (UI/L) & 36 & $21-102$ \\
CREAT (mg/dL) & 0,82 & $0,5-1,5$ \\
\hline
\end{tabular}

Devido à repetida presença de sombras de Gumprecht na série branca e linfocitose, o animal foi submetido à citologia aspirativa da medula óssea. $\mathrm{O}$ mielograma evidenciou presença de espículas de celularidade aumentada em $70 \%$. A série mieloide e eritróide foram observadas em quantidade normal, com discreto retardo maturativo na fase de rubrícito policromatofílico e presença de raras figuras de mitose e difícil observação do nucléolo, na forma matura. A série linfoide apresentou-se moderadamente elevada com predomínio de pequenos linfócitos típicos. Paralelamente, foi realizado a imunocitoquímica e citometria de fluxo, e foi observada uma reatividade cruzada positiva para os marcadores CD10 e CD22. Porém, os exames citoquímicos de Sudan negro e da Peroxidase foram negativos. De acordo com os resultados laboratoriais, o diagnóstico foi de leucemia de origem linfóide B.

Perante o diagnóstico laboratorial, o proprietário foi aconselhado pelo tratamento quimioterápico associado à esplenectomia. O proprietário optou somente pelo procedimento cirúrgico de esplenectomia, e o animal foi submetido à esplenectomia total e remoção do linfonodo regional para posterior exame histopatológico. $\mathrm{O}$ exame histopatológico do baço e linfonodo regional não apresentaram quaisquer alterações histopatológicas.

Foram realizados exames hematológicos e de bioquímica sérica (ALT e CREAT) em seis momentos distintos após a cirurgia: Momento 1 - quatro dias após; Momento 2 - 10 dias após; Momento 3 - 30 dias após; Momento 4 - 90 dias após; Momento 5 - 250 dias após; Momento 6 - dois anos após a cirurgia.

Os gráficos foram confeccionados utilizando-se o programa GraphPad Prism $5^{\circledR}$. Os valores dos eritrócitos, da hemoglobina, do hematócrito, das plaquetas, apresentaram-se dentro dos padrões de referência durante os seis momentos (Figuras 1, 2 e 3) e não foram observadas sombras de Gumprecht. Os valores dos eosinófilos, dos monócitos, permaneceram dentro dos parâmetros normais da espécie, porém, os valores de leucócitos e linfócitos absolutos apresentaram-se aumentados no $4^{\circ}$ dia e $10^{\circ}$ dia após a cirurgia, e nos momentos restantes observou-se uma diminuição e mantiveram-se dentro dos padrões de referência (Figura 4). Os valores da alanina aminotransferase e da creatinina apresentaram-se dentro dos padrões de referência durante os seis momentos (Figuras 5 e 6).

Figura 1: Resultados relativos à avaliação dos valores dos eritrócitos $\left(10^{6} / \mu \mathrm{L}\right)$ e hemoglobina $(\mathrm{g} / \mathrm{dL})$ durante seis momentos distintos após esplenectomia em cadela de raça maltesa, três anos de idade, $8 \mathrm{~kg}$ de peso corpóreo. Momento 1 - quatro dias após; Momento 2 - 10 dias após; Momento 3 - 30 dias após; Momento 4 - 90 dias após; Momento 5 - 250 dias após; Momento $6-2$ anos após a cirurgia.

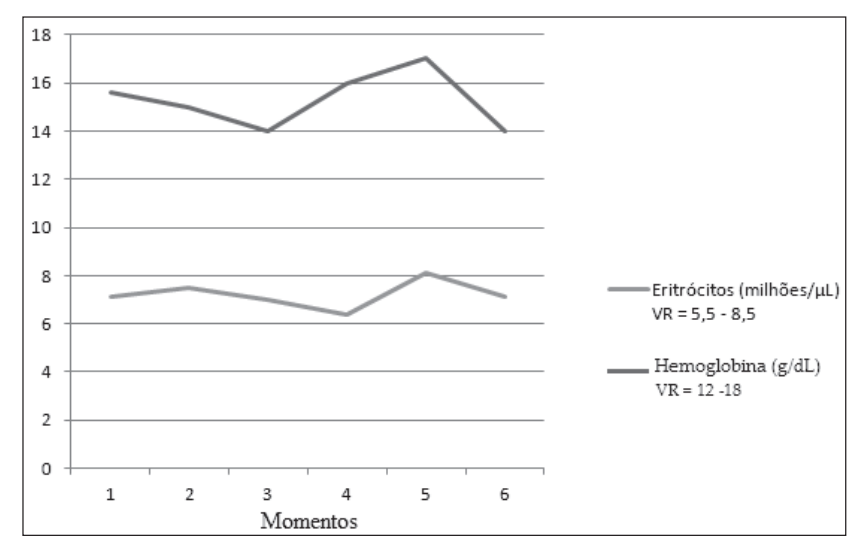


Figura 2: Resultados relativos à avaliação dos valores da hematócrito (\%) durante seis momentos distintos após esplenectomia em cadela de raça maltesa, três anos de idade, $8 \mathrm{~kg}$ de peso corpóreo. Momento 1 - quatro dias após; Momento 2 - 10 dias após; Momento 3 - 30 dias após; Momento 4 - 90 dias após; Momento 5 - 250 dias após; Momento 6-2 anos após a cirurgia.

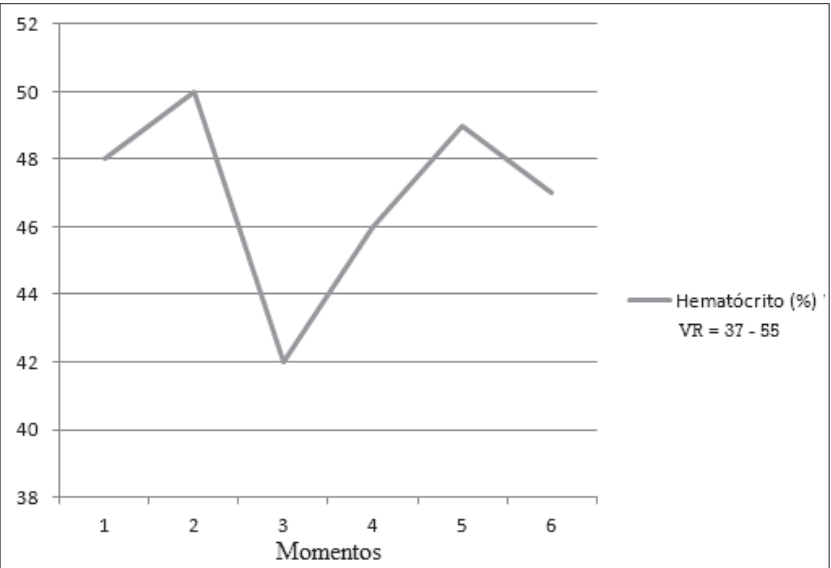

Figura 3: Resultados relativos à avaliação dos valores de plaquetas $(\mathrm{mil} / \mu \mathrm{L})$ durante seis momentos distintos após esplenectomia em cadela de raça maltesa, três anos de idade, $8 \mathrm{~kg}$ de peso corpóreo. Momento 1 - quatro dias após; Momento 2 - 10 dias após; Momento 3 - 30 dias após; Momento 4 - 90 dias após; Momento 5 - 250 dias após; Momento 6-2 anos após a cirurgia.

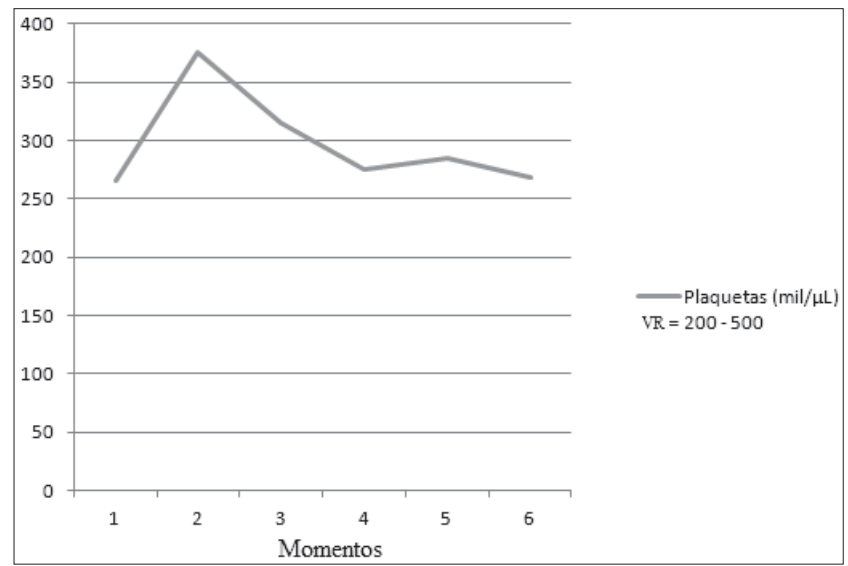

Figura 4: Resultados relativos à avaliação dos valores de leucócitos $(\mathrm{mil} / \mu \mathrm{L})$, neutrófilos segmentados $(\mathrm{mil} / \mu \mathrm{L})$, linfócitos $(\mathrm{mil} / \mu \mathrm{L})$, eosinófilos $(\mathrm{mil} / \mu \mathrm{L})$ e monócitos $(\mathrm{mil} / \mu \mathrm{L})$ durante seis momentos distintos após esplenectomia em cadela de raça maltesa, três anos de idade, $8 \mathrm{~kg}$ de peso corpóreo. Momento 1 - quatro dias após; Momento 2 - 10 dias após; Momento 3 - 30 dias após; Momento 4 - 90 dias após; Momento 5 - 250 dias após; Momento $6-2$ anos após a cirurgia.

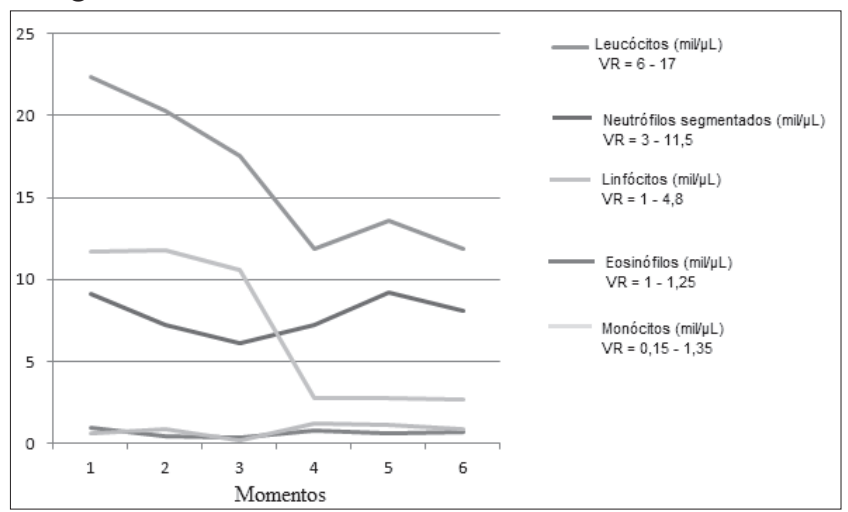

Figura 5: Resultados relativos à avaliação dos valores de alanina aminotransferase (UI/L) durante seis momentos distintos após esplenectomia em cadela de raça maltesa, três anos de idade, $8 \mathrm{~kg}$ de peso corpóreo. Momento 1 - quatro dias após; Momento 2 - 10 dias após; Momento 3 - 30 dias após; Momento 4 - 90 dias após; Momento 5 - 250 dias após; Momento 6 -2 anos após a cirurgia.

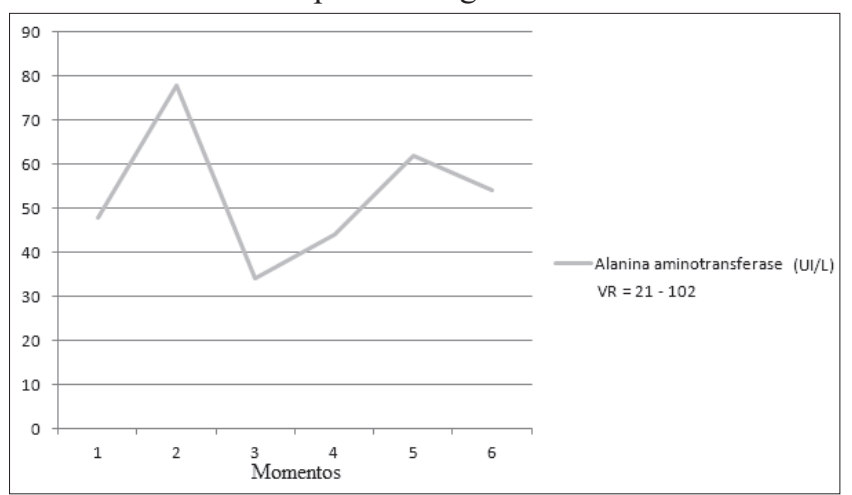


Figura 6: Resultados relativos à avaliação dos valores de creatinina $(\mathrm{mg} / \mathrm{dL})$ durante seis momentos distintos após esplenectomia em cadela de raça maltesa, três anos de idade, $8 \mathrm{~kg}$ de peso corpóreo. Momento 1 - quatro dias após; Momento 2 - 10 dias após; Momento 3 - 30 dias após; Momento 4 - 90 dias após; Momento 5 - 250 dias após; Momento 6-2 anos após a cirurgia.

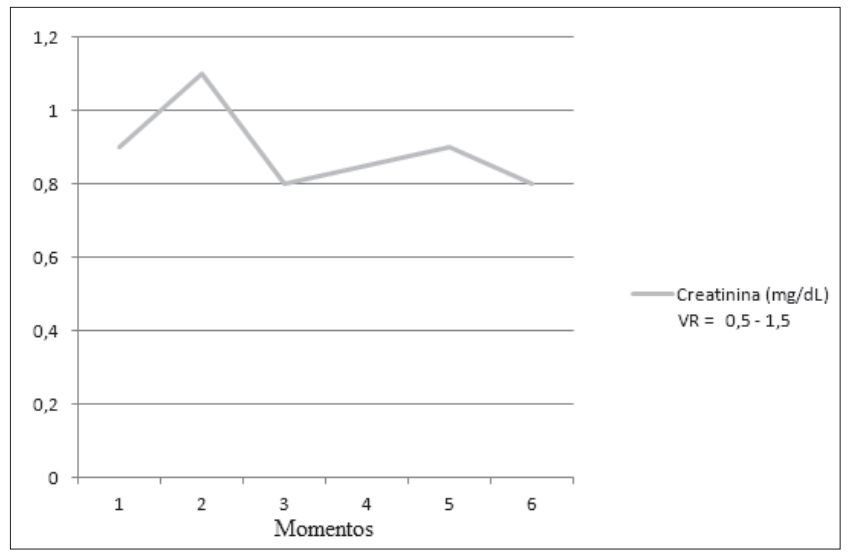

Dois anos após a esplenectomia, o animal foi submetido à citologia aspirativa da medula óssea, e o mielograma não evidenciou alterações dignas de referência na série mieloide, eritroide e linfoide. A imunocitoquímica e citometria de fluxo foram negativas para os marcadores CD10 e CD22.

\section{Discussão}

$\mathrm{Na}$ atualidade, as leucemias em pequenos animais constituem uma das afecções neoplásicas pouco diagnosticadas, podendo estar relacionada aos diversos diagnósticos diferenciais e a pouca utilização de técnicas laboratoriais de diagnóstico mais especificas (FRANCO, 2008). Em pacientes humanos, a frequência de novos casos anuais de leucemia linfocítica é de duas a três para cada 100.000 habitantes (ALTARRIBA et al., 2002). Meyer e Harvey (1998) e Jacobs et al. (2002), descreveram maior incidência desse tipo de neoplasia em cães de meia-idade e cães idosos, diferentemente do verificado no presente caso. A ocorrência das leucemias em cães é rara, representando menos de $10 \%$ de todas as afecções linfoproliferativas em pequenos animais (SHIMOMURA, 2006; LORENZI, 2006). O presente trabalho descreveu um caso de leucemia linfocítica em uma cadela de três anos de idade, considerado incomum, visto que a afecção é relatada com maior porcentagem em cães com idade média de 9,4 anos (TILLEY, 2003; SHIMOMURA, 2006; DOBSON, 2006).

Supôs-se que a etiologia da leucemia linfocítica do presente caso foi de ocorrência espontânea (SHIMOMURA, 2006), visto que não foi relatado qualquer tipo de exposição do animal à radiação ionizante, vírus oncogênicos ou agentes químicos. Segundo Tilley (2003) e Shimomura (2006), esses fatores são importantes para o desencadeamento neoplásico pela quebra, alteração e integração da oncogênese no DNA das células. Por outro lado, não foi observado comprometimento da imunidade celular (Tabela 1 e 4), em conformidade com Tilley (2003).

A leucemia linfocítica foi diagnosticada durante uma consulta de rotina, sendo observada leucocitose devido à linfocitose acentuada, coerente com a literatura (SHIMOMURA, 2006; DOBSON, 2006; FRANCO, 2008). Os sinais clínicos, considerados inespecíficos, como anorexia, perda de peso, vômito, diarreia intermitente, poliúria, polidipsia e pirexia, relatados por Shimomura (2006) e Dobson (2006), não foram observados no presente caso. Alencar et al. (2008), descreveram um caso de leucemia linfocítica crônica em cadela de nove anos de idade, apresentando anorexia, dificuldade locomotora, esplenomegalia e hepatomegalia, e os sinais clínicos foram relacionados com a cronicidade da doença.

Segundo Shimomura (2006), o diagnóstico citológico pode ser obtido com uso de esterase cloroacetato, fosfatase alcalina, esterases não específicas, fosfatase ácida, beta-glucoronidase e azul de toluidina, entre outros. Contudo, no presente relato o animal foi submetido à citologia aspirativa da medula óssea e posterior mielograma, imunocitoquímica e citometria de fluxo, de acordo com a literatura (SHIMOMURA, 2006). Segundo Franco (2008), a identificação citoquímica das células neoplásicas pode ser realizada em esfregaços de sangue periférico ou de medula óssea, podendo identificar a presença de diferentes enzimas no citoplasma dos blastos que auxiliam no estabelecimento da sua origem. Em geral, as peroxidases ou Sudan Black B são positivos para blastos M1, M2, M4, M5 e M6, e negativos para leucemia aguda indiferenciada (SHIMOMURA, 2006).

A variação dos valores dos leucócitos e linfócitos absolutos auxiliou na identificação de uma eventual leucemia linfocítica. Segundo Grindem et al. (2002), o exame citológico do aspirado de medula óssea ou exame histopatológico de biópsia é imprescindível para descartar outras possíveis causas de linfocitose. A linfocitose absoluta é o principal critério para suspeita de leucemia linfocítica em cães e pacientes humanos (SHIMOMURA, 2006; NIERO-MELO et al., 2006), considerando linfocitose acentuada quando os valores são maiores que 20.000/uL, sendo patognomônica de leucemia linfocítica (SHIMOMURA, 2006), similar ao presente relato, que foi observado valor de linfócitos de 38.800/uL no primeiro dia de consulta. A ausência de anemia do tipo normocítica normocrômica observada no presente caso não corroborou com a literatura (SHIMOMURA, 2006). Por outro lado, a linfocitose acentuada pode resultar, também, de uma estimulação antigênica persistente causada por algum agente infeccioso (FRANCO, 2008). Desse modo, é importante descartar outras possíveis causas infecciosas que possam induzir a linfocitose acentuada e persistente. Contudo, a presença de linfocitose devido às causas infecciosas geralmente desaparece rapidamente com o tratamento da afecção infecciosa.

Para além da linfocitose persistente, a presença de sombras de Gumprecht no hemograma auxiliou na confirmação da suspeita de leucemia linfocítica, similar ao citado pela literatura (MATUTES et al., 2007; NOWAKOWSKI et al., 2009), porém, não é considerado um elemento confiável para diagnóstico definitivo da afecção (DUSSE et al., 2013). Segundo Dusse et al. (2013), a presença das sombras de Gumprecht gradualmente foram perdendo importância no diagnóstico definitivo da leucemia linfocítica, visto que em afecções virais, artrites, lúpus eritematoso, entre outros, a linfocitose esta presente, e os linfócitos circulantes estão susceptíveis a lise.

No momento da primeira consulta, o exame hematológico revelou que os leucócitos, neutrófilos segmentados e os linfócitos encontravam-se com valores acima dos padrões 
de referência, diminuindo após antibioticoterapia, porém, permanecendo acima dos valores de referência. Este aumento deveu-se à presença da leucemia linfocítica subclínica.

Em relação às plaquetas foi observado um aumento brusco em seus valores no décimo dia após a esplenectomia (Figura 3), e discreta diminuição até dois anos após a cirurgia. A variação, com os valores permanecendo dentro do padrão de referência, esteve relacionada com a esplenectomia, visto que o baço participa na hematopoiese e na hemocaterese.

O tratamento da leucemia em pequenos animais é controverso, visto que a quimioterapia é indicada em animais com linfocitose acentuada, anemia e trombocitopenia; e a esplenectomia em casos de presença de anemia imunomediada e trombocitopenia (BIONDO, 2005). De acordo com Shimomura (2006), os animais que não apresentem anemia, trombocitopenia e leucócitos totais menor que $60.000 / \mathrm{uL}$ podem não necessitar de tratamento quimioterápico. No presente caso, o animal apresentou somente leucocitose $(<60.000 /$ $\mathrm{uL}$ ), linfocitose persistente, sombras de Gumprecht e ausência de anemia e trombocitopenia. Durante o exame ultrassonográfico não foram observadas metástases em baço, linfonodos e fígado, contrariamente citado por Biondo (2005). Atualmente, em pacientes humanos, está sendo utilizada a terapia celular para o tratamento das leucemias linfocítica B (BRENTJENS et al., 2013; GRUPP et al., 2013), porém, este tipo de tratamento não se encontra disponível na medicina veterinária.

Foi decidido somente pelo tratamento cirúrgico esplenectomia, por opção do proprietário, mesmo não sendo observada anemia hemolítica imunomediada secundária ou trombocitopenia grave que justificasse o procedimento, segundo a literatura (TILLEY, 2003; BIONDO, 2005). Sugere-se que a esplenectomia preveniu uma possível anemia hemolítica imunomediada secundária que poderia ocorrer devido à ausência de tratamento quimioterápico. A esplenectomia de alguma forma contribuiu com o tratamento, visto que não foi realizado qualquer tipo de tratamento associado.

A sobrevida do animal foi coerente com a literatura (SHIMOMURA, 2006), relatando sobrevida acima de dois anos em cães não submetidos ao tratamento quimioterápico. Porém, o tempo médio de sobrevida após o diagnóstico e início da quimioterapia é de 452 dias (TILLEY, 2003).

\section{Conclusões}

De acordo com as características do presente relato de caso pode-se concluir que a leucemia linfocítica pode acometer animais jovens. O valor acentuado dos linfócitos observados no hemograma e presença proliferativa de linfócitos na medula óssea leva a confirmação da leucemia linfocítica. O mielograma, imunocitoquímica e citometria de fluxo continuam sendo exames determinantes para o diagnóstico da leucemia linfocítica canina. $\mathrm{O}$ tratamento exclusivamente pela esplenectomia, em animal jovem e sem sinal clínico, contribui para a ausência de recidiva da afecção durante dois anos.

\section{Referências}

ALENCAR, N. X. et al. Leucemia linfocítica crônica em cão: relato de caso. Revista Brasileira de Cirurgia Veterinária, v. 15, n. 3, p. 126-128, 2008.
ALTARRIBA, M.C.M; GRAU, M. L.; GALLARDO, C. Intentando mejorar el pronóstico y la supervivencia del mieloma y la leucemia linfoide crónica. Medicina general, v. 43 , p. 247-251, 2002.

BAIN, B. J. Diagnóstico em leucemias. 2. ed. Rio de Janeiro: Revinter, p.76-78, 2003.

BIONDO, A. W. Doenças Mieloproliferativas. In: SIMPÓSIO DE PATOLOGIA CLÍNICA VETERINÁRIA DA REGIÃO SUL DO BRASIL. 2., 2005. Anais...Porto Alegre: UFRGS, 2005. p. 36- 42.

BRENTJENS, R. J. et al. CD19-targeted T cells rapidly induce molecular remissions in adults with chemotherapy refractory acute lymphoblastic leukemia. Science

Translational Medicine. v. 5, p. 177, 2013.

DOBSON, J.; VILLIERS, E.; MORRIS, J. Diagnosis and management of leukaemia in dogs and cats. In Practice, v. 28 , p. 22-31, 2006.

DUSSE, L. M. S. et al. Sombras de Gumprecht: quando usar essa terminologia? Jornal Brasileiro de Patologia e Medicina Laboratorial, v. 49, n. 5, p. 320-323, 2013.

FRANCO, D. G. et al. Leucemia canina: aspectos laboratoriais e clínicos - revisão de literatura. Veterinária e Zootecnia, v. 15, n. 3, p. 15-18, 2008.

GRINDEM, C. B.; NEEL, J. A.; JUOPPERI, T. A. Cytology of bone marrow. The Veterinary Clinics of North America - Small Animal Practice, v. 32, p. 1313 - 1374, 2002.

GRUPP, S. A. et al. Chimeric antigen receptor-modified T cells for acute lymphoid leukemia. The New England Journal of Medicine, v. 368, p. 1509-1518, 2013.

HARVEY, J. W. Atlas of Veterinary Hematology - Blood and bone marrow of domestic animals. Philadelphia, Saunders, p. 228, 2001.

JACOBS, R. M.; MESSICK, J. B.; VALLI, V. E. Tumors of the Hemolymphatic System. In: MEUTEN, D.J. (Ed.) Tumors in Domestic Animals. Ames: Iowa State Press, p. 119-198, 2002.

JAIN, N. C. Schalm's Veterinary Hematology. 4 Ed. Philadelphia: Lea \& Febiger, p. 136. 1986.

KANEKO, J. J.; HARVEY, J. W.; BRUSS, M. L. Clinical Biochemistry of Domestic Animals. 6 ed. San Diego: Academic Press, p. 212-221, 2008.

LORENZI, T. F. Manual de hematologia, propedêutica e clínica. 4. ed. Rio de Janeiro: Medsi Editora Médica e Científica Ltda., p.87-95, 2006.

MATUTES, E.; WOTHERSPOON, A.; CATOVSKY, D. Differential diagnosis in chronic lymphocytic leukaemia. Best Practice and Research Clinical Haematology, v. 20, n. 3, p. 367-384, 2007. 
MEYER, D. J.; HARVEY, J. W. Evaluation of leukocytic disorders. In:__. Veterinary Laboratory Medicine Interpretation and diagnosis. Philadelphia: W. B. Sounders Company. p. 83-110, 1998.

NIERO-MELO, L. et al. Diretrizes para diagnóstico morfológico em síndromes mielodisplásicas. Guidelines for morphological diagnosis of myelodysplastic syndromes.

Revista Brasileira de Hematologia e Hemoterapia, v. 28, n. 3, p. 167-174, 2006.

NOWAKOWAKI, G. S. et al. Percentage of smudge cells on routine blood smear predicts survival in chronic lymphocytic leukemia. Journal of Clinical Oncology, v. 27, n. 11, p. 1844-1849, 2009.

SHIMOMURA, J. Z. et al. Características Clínicas da Leucemia Linfocítica Crônica em cão. Ciências Agrárias e Saúde, v.6, p. 68-72, 2006.

TILLEY, L. P.; SMITH JR., F. W. K. Consulta Veterinária em 5 minutos. Espécies canina e felina. $2^{\text {a }}$ Ed. São Paulo: Malone, p. 112-116, 2003.

Recebido em: 17.07.2015

Aceito em: 29.08.2016 